\title{
Coronavirus Pandemic - SARS-CoV-2 in Orthopedics and Trauma Surgery
}

\section{Coronavirus-Pandemie - SARS-CoV-2 in Orthopädie und Unfallchirurgie}

Authors

Michael Müller ${ }^{1}$, Ulrich Stöckle ${ }^{1}$, Andrej Trampuz ${ }^{1}$, Stephan Felix², Axel Kramer ${ }^{3}{ }^{\mathbb{D}}$, Georgi Wassilew ${ }^{4}$

Affiliations

1 Centrum für Muskuloskeletale Chirurgie Charité Universitätsmedizin Berlin

2 Klinik für Kardiologie, Angiologie, Pneumologie/Infektiologie und Intensivmedizin, Universitätsmedizin Greifswald

3 Institut für Hygiene und Umweltmedizin, Universitätsmedizin Greifswald

4 Klinik für Orthopädie und Orthopädische Chirurgie, Universitätsmedizin Greifswald

Key words

corona virus pandemic, SARS-CoV-2, orthopedics, traumatology, COVID-19

Schlüsselwörter

Coronavirus-Pandemie, SARS-CoV-2, Orthopädie, Unfallchirurgie, COVID-19

published online $\quad 05.11 .2020$

Bibliography

Z Orthop Unfall 2021; 159: 25-30

DOI 10.1055/a-1208-0182

ISSN 1864-6697

(c) 2020. Thieme. All rights reserved.

Georg Thieme Verlag KG, Rüdigerstraße 14,

70469 Stuttgart, Germany

Correspondence

PD Dr. med. Michael Müller

Centrum für Muskuloskeletale Chirurgie,

Charité - Universitätsmedizin Berlin

Charitéplatz 1, 10117 Berlin

Phone: 030/450-65-2455, Fax: 030/450-51-5911

michael.mueller@charite.de

\section{ABSTRACT}

The corona virus has spread worldwide since it first appeared in China and represents a pandemic of unprecedented magnitude. The pandemic has not only social and economic effects, but even more impressive effects on the health system. If the virus spreads uncontrollably and rapidly, there is a risk of an unpredictable increase of patients with COVID-19 disease re- quiring hospital treatment. The capacities of a hospital can quickly reach the limit and consequently patients can no longer be adequately treated. Therefore, in the acute phase of the pandemic, it is necessary to release all hospital resources for the treatment of COVID-19 patients. Strict hygiene regulations must also be observed in order to prevent the virus from spreading unexpectedly in the hospital in order to protect patients and hospital staff. Elective operations and outpatient clinics must be cancelled in the acute phase. Special hygiene measures must be observed for urgent and unpostponable operations. These relate to the admission of the patients, the accommodation in the ward and the operative care in the operating room. In the post-acute phase, a normal surgical program can be resumed step by step. In this phase, however, clear hygiene regulations must also be observed. Regular medical meetings taking into account the current pandemic situation and the occurrence of new infections must be carried out in the hospital and the occupancy of the ward and operating room adjusted accordingly. To what extent the situation for the treatment of patients in orthopedics and trauma surgery will normalize cannot be predicted at the present time.

\section{ZUSAMMENFASSUNG}

Das Coronavirus hat sich seit dem ersten Auftreten in China weltweit verbreitet und stellt eine Pandemie von bisher nicht gekanntem Ausmaß dar. Die Pandemie hat nicht nur gesellschaftliche und wirtschaftliche Auswirkungen, sondern erst recht eindrückliche Auswirkungen auf das Gesundheitssystem. Bei einer unkontrollierten und raschen Ausbreitung des Virus besteht die Gefahr eines unvorhersehbaren Anstiegs von Patienten mit einer behandlungsbedürftigen COVID-19Erkrankung. Die Kapazitäten eines Krankenhauses können dadurch rasch an das Limit kommen und Patienten nicht mehr adäquat behandelt werden. Deshalb ist es in der akuten Phase der Pandemie notwendig, jegliche Ressourcen eines Krankenhauses für die Behandlung von COVID-19-Patienten freizugeben. Ebenfalls müssen strenge Hygienevorschriften eingehalten werden, um gerade im Krankenhaus eine unvorhergesehene Virusverbreitung zu verhindern, um damit Patienten und Krankenhauspersonal zu schützen. Elektivoperationen und Ambulanzsprechstunden müssen in der akuten Phase abgesagt werden. Für dringliche und nicht verschiebbare Opera- 
tionen sind spezielle Hygienemaßnahmen einzuhalten. Diese beziehen sich auf die Aufnahme der Patienten, die Unterbringung auf Station und die operative Versorgung im OP. In der postakuten Phase kann schrittweise ein normales OP-Programm wieder aufgenommen werden. In dieser Phase sind aber auch klare Hygienevorschriften einzuhalten. RegelmäBige Besprechungen unter Berücksichtigung der aktuellen
Pandemielage und des Auftretens von Neuinfektionen sind im Krankenhaus vorzunehmen und entsprechend die Auslastung von Station und OP anzupassen. Inwieweit sich die Lage für die Behandlung von Patienten in Orthopädie und Unfallchirurgie wieder normalisieren wird, lässt sich zum gegenwärtigen Zeitpunkt noch nicht vorhersagen.

\section{Introduction}

The new coronavirus SARS-CoV-2 has caused a global pandemic which has spread with an impressive and alarming dynamic, with sustained effects on society, the economy and the health system. The infection numbers continue to grow so the likelihood of being faced with patients who are infected or are SARS-CoV-2 carriers in areas such as orthopaedics and trauma surgery is also increasing.

The virus spreads mainly via droplets and aerosols from the respiratory tract, with small aerosol particles floating in the air for several hours, and also via direct personal contact or contact surfaces [1 -4]. The treating hospital staff in the admission unit, outpatient clinic, ward and operating theatre are therefore highly at risk of being infected by carriers and developing the disease or at least unconsciously spreading the virus further [5]. Epidemiological studies from China confirm that the infection risk for hospital staff is extremely high, with mortality rates up to more than $3 \%$ [6-8]. The Italian national professional association of doctors and dentists reports that over 131 medical colleagues died of COVID-19 in Italy up to 17.4.2020 (FNOMCeO.it). It should be pointed out that a high infection risk arises not only from symptomatic COVID-19 patients but also from asymptomatic SARSCoV-2-positive carriers. Recent studies show that the virus load in nasal and pharyngeal swabs from asymptomatic patients is similar to that of symptomatic patients, which indicates that infected persons without symptoms can transmit the virus with the same infectiousness [1]. Strict hygiene procedures are therefore necessary when treating patients during a SARS-CoV-2 pandemic.

\section{Procedure in the Acute Pandemic}

In an acute pandemic situation, it is necessary to reduce to a minimum the possibilities for contact and transmission in order to diminish the risk of involuntary spread and infection of staff and other patients. It is therefore absolutely essential in a hospital to postpone all non-urgent elective operations, which make up a significant proportion, especially in orthopaedics (https://dgou.de/ news/covid-19-spezial). This frees up important resources, especially of fixed staff, who are urgently needed for the possible care of COVID-19 patients. This also reduces regular patient numbers and thus the risk of uncontrolled spread of SARS-CoV-2 in the hospital. The freed-up ward and bed capacity is necessary for spatial separation into areas for patients with COVID-19 and patients who have tested positive for SARS-CoV-2 and ordinary areas for non-infected patients. In outpatient clinics, too, patient attendance should be reduced to urgent indications and follow-up only or possibly even cancelled completely in the case of a highly acute phase.

Naturally, there are indications in orthopaedics and trauma surgery that do not allow a postponement and that require acute or early management. These include, in particular, dislocated and unstable fractures, life-threatening injuries/trauma, malignant disease, injuries or diseases associated with immobility or with a neurological component as well as infections of joints, implants and soft tissues [9].

\section{Wearing of Face Masks}

Face masks have been shown to reduce the release of droplets through coughed or exhaled contaminated air and to reduce the distance of spread [10]. The CDC (Center for Disease Control and Prevention) therefore recommends wearing a mask especially in areas where there is an increased risk of transmission (https://www.cdc.gov/coronavirus/2019-ncov/ prevent-getting-sick/prevention.html).

In the present pandemic situation, every patient admitted to hospital must be regarded as a potential carrier of the SARS-CoV-2 virus and should be given a mask on admission to hospital. A mask should also be worn by all the staff in the hospital [10]. The same applies for essential outpatient care.

\section{Hand Hygiene}

In addition to the hand disinfection dispensers in every patient's room, hand disinfection dispensers should also be provided at the entrance to the hospital (and outpatient clinics) and on the ward. All alcohol-based hand disinfectants with the declaration “limited virucidal" are effective against coronaviruses [3].

\section{Admission Screening, Clinical Evaluation and Resulting Sequence ( $>$ Fig. 1)}

To prevent infection of hospital staff and avoid uncontrolled spread of the virus in the hospital, a certain admission procedure should be followed strictly for all patients. It is recommended to take a swab from every patient who is admitted to hospital [11]. Provided there is no evidence of COVID-19 clinically or from the history (see below), admission should be to a separate assessment ward ("unsafe area"). The operation should be performed only after the test result is obtained, if acceptable, and the patient should be transferred to an ordinary ward or, if necessary to a SARS-COV-2/COVID-19 ward ( $\triangleright$ Fig. 1).

A swab should also be taken, if possible, when acute operation is indicated and the patient has to be transferred directly from the emergency unit to the operating theatre. Clinical staff should be reduced to an acceptably small number and so should the dura- 
tion and frequency of staff-patient contacts. If urgency permits, the operation should be performed only when the swab result is available. It should be pointed out that a non-positive swab does not exclude infection with SARS-CoV-2 with certainty as an incubation period of up to 14 days is accepted [12]. The patient can therefore still test positive for SARS-CoV-2 and exhibit symptoms during the subsequent hospitalisation after surgery and a negative test on admission. The sensitivity and specificity of current tests cannot yet be determined with certainty because of the limited studies. Initial results, however, indicate a sensitivity of about $75 \%$ to $95 \%$ depending on the test system $[12,13]$.

Apart from the test, clinical symptoms of infection should always be noted. The most frequent symptoms are fever in $82-$ $87 \%$, cough in $36.5-44 \%$ and anosmia in $19-59.4 \%$, followed by sore throat, headache, pharyngitis, rhinorrhoea, weakness, fatigue and also gastrointestinal symptoms in about $10 \%[14,15]$. In the first systematic review, no differences in the incidence of these symptoms were found between patients with severe or mild and moderate disease [16]. Only dyspnoea occurred more often in severe cases [15-17]. The following disease types are distinguished according to severity:

\section{WHO Classification of COVID-19 [18]}

\section{Mild cases}

The clinical symptoms are mild and no manifestations of pneumonia are found on imaging.

\section{Moderate cases}

Patients with clinical signs of pneumonia (fever, cough, dyspnoea, rapid respiration), but no signs of severe pneumonia, including $\mathrm{SpO} 2 \geq 90 \%$ in room air. Signs of pneumonia can be seen on imaging.

\section{Severe cases}

Adults with clinical signs of pneumonia (fever, cough, dyspnoea, rapid respiration), but no signs of severe pneumonia plus one of the following criteria:

- Respiratory rate $>30$ respirations/min;

- Oxygen saturation < $90 \%$ at rest;

- Arterial partial pressure of oxygen (PaO)/oxygen concentration (FiO) $<300 \mathrm{mmHg}$.

- Patients with > 50\% lesion progression within 24 to 48 hours in lung imaging should be treated as severe cases.

\section{Critical cases}

Meet one of the following criteria:

- Development of respiratory failure (ARDS) that requires mechanical or extracorporeal ventilation

- Presence of shock

- Other organ failure

Apart from the symptoms, the history of risk, such as a stay in risk regions or locations, contact with positive persons, work in medical care or in care homes should be considered. If there are any

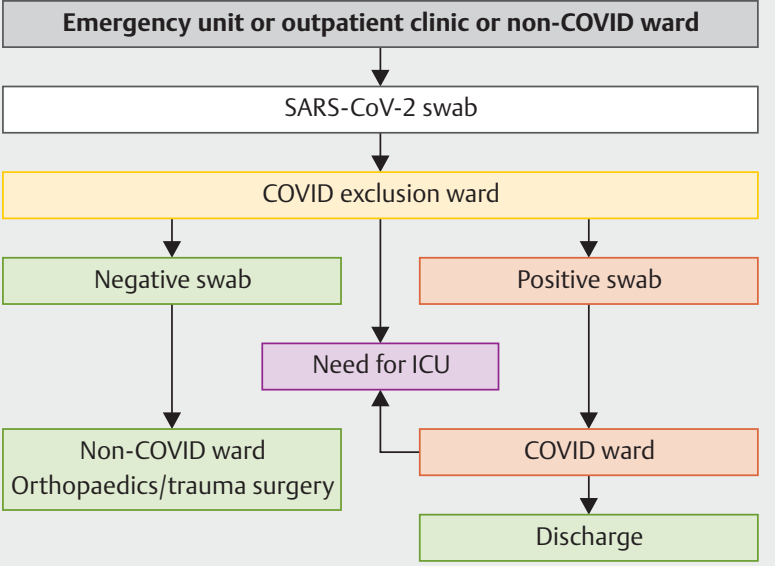

- Fig. 1 Flowchart of organisation and admission of patients to an orthopaedic/trauma surgery department or clinic.

clinical abnormalities, low-dose CT of the thorax can be useful in addition to the nasopharyngeal swab [19].

Finally, patient accommodation in an ordinary ward or in the isolation area for COVID-19 should be arranged ( $\bullet$ Fig. 1).

\section{Personal Protective Equipment (PPE)}

For operations that cannot be postponed, every patient should be regarded as SARS-CoV-2-positive and wearing of personal protective equipment (PPE) is recommended. This applies just the same as in the case of a history or clinical suspicion of COVID-19 infection. Personal protective equipment in the operating theatre consists of an insulating gown (high performance), gloves, goggles/ face shield and particle-filtering mask (FFP2 if suspected, FFP3 if disease).

PPE is essential and effective in protecting oneself against infection. It is important to ensure that it is donned and doffed correctly. It became apparent in the Ebola outbreak how important correct donning and doffing of PPE is to prevent infection, especially when removing the PPE [20]. Based on the experiences from the Ebola epidemic, it is recommended that staff are trained by the hygiene team in putting on and taking off PPE [21].

\section{Procedure in the Operating Theatre}

As mentioned above, the SARS-CoV-2 virus is transmitted mainly via aerosols and contact surfaces. There is therefore a risk of infection in the operating theatre for all persons who are in the operating theatre. The virus is located in the pharynx and lungs and in the mucosa. However, there is also evidence that a few patients with SARS-CoV-2 can have viraemia, so the risk of blood-borne transmission of the virus cannot be excluded [22,23]. An increased infection risk overall for the entire OT team must be assumed since not only blood, bone components or other tissue residues can be sprayed during major operations in orthopaedics and trauma surgery, but blood dust is also produced, e.g., by 
hammer blows, which behaves similarly to an aerosol. Accordingly, appropriate precautions to protect staff should also be taken in the OT. The role of electrocautery vapour has not yet been clarified. It should therefore be omitted, or additional fume extraction should be used. Reserving an operating theatre exclusively for SARS-CoV-2 patients is recommended and only these patients should be operated on there. Overall, however, there is still no clear evidence for this. It should be ensured that patients are ventilated in closed systems in order to avoid aerosol release.

\section{Surgical operations in suspected or confirmed SARS-CoV-2 positive patients}

Operating theatre and staff PPE requirements, room ventilation systems

There is no evidence for the following considerations. However, the following conclusions can be drawn from a risk assessment:

- OTs with laminar air flow (LAF) (room class 1a) have considerably greater ventilation volume flow than OTs with mixed air (room class Ib), so aerosol dilution takes place faster in a theatre with LAF ventilation. Operating rooms with LAF also ensures additional protection for the operation team and patient due to the directed instead of merely mixed air flow in the operation area. Provided the extracted air from the OT flows directly to the outside via an extractor unit, the OT can be used without restriction. The usual PPE would suffice in the OT environment. However, if adjacent rooms are ventilated with the "exhaust air" from the OT via overflow technology, contamination of these rooms cannot be excluded. Since it is not known how long the coronavirus persists in room air, the risk is incalculable so no COVID-19 patients should have surgery in such OTs.

If the room ventilation system can be switched to negative pressure, this ensures that no viruses can get into adjacent rooms by overflow from the OT. Accordingly, an OT with negative pressure is preferable. When the doors are opened, the negative pressure is immediately interrupted and air exchange with the environment takes place during door opening. The doors must therefore be kept closed throughout the operation.

- Room class Ib OTs (without LAF) are associated with a higher contamination risk for the OT team because of the turbulent mixed flow and much lower ventilation volume with turbulence of the resulting aerosols. FFP3 masks should therefore be worn in these operating theatres. Use of positive-pressure body exhaust suits might possibly achieve greater protection of the operating team [24, 25].

- Room class II OTs and procedure rooms with a room ventilation system have low ventilation volume flows and often no sterile filters. Therefore, these should not be considered for operations in COVID-19 patients.

- OTs without a ventilation system are also not possible as there is no dilution of released aerosols and the highest aerosol concentration escapes after the door is opened at the end of the operation.

\section{Sterile supplies, access restrictions, OT requirements}

- Preparation of all the required operation sets and tables takes place outside the operating theatre in the sterile area.

- The theatre nurses in the buffer space (sterile area) are responsible for delivering the operation material.

- Non-relevant staff are excluded from entering the OT.

- During operation, the buffer space and operating theatre must be tightly closed.

- Anaesthetic induction, including intubation and extubation, should be performed separately, outside the operating theatre, in the induction and recovery room. Only the anaesthetist and anaesthetic nurse should be present. For these persons also, special rules apply for intubation and extubation of SARS-CoV-2-positive patients [26].

- At the end of the operation, the operating theatre surfaces should be disinfected with a virucidal disinfectant; active oxygen agents such as Descogen liquid are suitable.

\section{Protective clothing}

- The entire OT staff should put on PPE before entering the buffer space. This includes double surgical caps, face mask (FFP2, ideally FFP3) with a standard surgical mask over it, goggles or mask with protective shield, boots, unsterile medical disposable gloves.

- The surgeons and operating nurses don sterile surgical gowns and sterile gloves over the PPE.

- Patients should wear a surgical cap and mask.

\section{Operation indications in patients with COVID-19}

The indication for surgery in patients with COVID-19 should be considered with extreme caution and only after consultation with internal medicine and anaesthesiology colleagues. Operations should usually only be performed to preserve life or ensure stable and pain-free positioning or mobilisation of the patient, and only the most minimally invasive and time-saving operation technique should be used.

\section{Isolation of COVID-19 patients or suspected cases on the ward}

COVID-19 patients including suspected cases should be treated in a separate and strictly segregated ward, observing isolation techniques. These include the following criteria:

- Isolation in an isolation room with anteroom for donning and doffing PPE

- Each patient is given a face mask (simple). Protective measures and independent hand disinfection are explained.

- The number of contacts between patient and doctor/nursing staff should be reduced to the minimum

- Visits to the patient are not permitted.

- The patient communicates with friends or relatives exclusively by mobile phone/tablet/notebook/telephone

- Nursing staff and doctors who treat SARS-CoV-2-positive patients should be rostered only for these, wherever possible. All staff involved in their care should be screened weekly for SARSCoV-2.

- Several SARS-CoV-2-positive patients can be accommodated together in one room. 


\section{Necessary measures in the inpatient area}

In the inpatient area, SARS-CoV-2-positive patients who are suffering from symptoms should be monitored adequately and supported with oxygen delivery when needed.

- Regular temperature monitoring

- Monitoring of oxygen saturation using a pulse oximeter as required

- Give oxygen when necessary if there is a drop in PO2 saturation $<94 \%$ in room air

If the patient's general condition deteriorates, especially if somnolence, delirium, dyspnoea or a fall in saturation develops, the respiratory rate, blood pressure and pulse should also be monitored.

- Measurements of respiratory rate

- Measurement of blood pressure and pulse

\section{Additional laboratory tests and extended imaging}

Laboratory tests should be performed regularly and computed tomography should be performed if there is a deterioration in general condition:

- Basic parameters: FBC, CRP, D-dimer, procalcitonin, interleukin-6 (IL6), angiotensin III (ATIII)

- Extended: renal parameters/liver enzymes

- CT imaging if there is visible deterioration

\section{Need for transfer to ICU}

If the patient's general condition deteriorates, prompt transfer to the ICU should take place [27]. The following criteria are decisive:

- Respiratory rate > 30 respirations/min;

- Oxygen saturation < $93 \%$ at rest (without giving O2);

- Arterial partial pressure of oxygen ( $\mathrm{PaO}) /$ oxygen concentration $(\mathrm{FiO})<300 \mathrm{mmHg}$.

- Patients with $>50 \%$ lesion progression within 24 to 48 hours in lung imaging should be treated as severe cases.

\section{Outlook}

The aim of the current society lockdown measures, which include concentrating the health system maximally on the pandemic, is to reduce the speed of dissemination of the virus and avoid an uncontrolled rate of increase. This is the only way to adjust the rate of COVID-19 patients who require treatment in hospital to the available healthcare resources. This necessity is undisputed and these measures currently show the desired success. It is clear that this not only fights the virus but prevents it from spreading rapidly. When the measures are loosened, unnoticed and uncontrolled infections can occur at any time with the same dangerous consequences. Only when more than $66 \%$ of the population is immune (so-called herd immunity) or a vaccine is developed will there probably be no further risk of uncontrolled spread. Herd immunity is based on the observation that infected individuals transmit the virus to two to three other persons on average. If more than two of the three people in the environment are immune, the virus reaches a dead end. However, a long-term lockdown of the health systems is not possible in the long run because of the other patients in need of treatment that is postponed in this type of crisis. Degenerative joint and spinal disorders that require surgical treatment cannot be delayed indefinitely. Immobilisation, chronic pain problems and major physical restrictions are the consequence of a protracted delay in treatment, with the risk of developing further health problems such as joint stiffness, muscle atrophy, deformities or effects on other joints or organs including the risk of depression. A solution is therefore required. From our point of view, regular operations should be resumed gradually, taking into account the current infection numbers and epidemiological developments in the foreseeable future, naturally allowing for the current pandemic situation, the hospital's free resources and the available staff, bed and ICU capacity. The responsible departments should meet daily and weekly to discuss the room and operating capacities that can be planned, depending on the overall situation. Every patient admitted for elective surgery should continue to have a swab taken. Assuming an incubation period of up to 14 days, every elective patient should be advised to self-isolate for 14 days prior to hospital admission. The operation is performed only after the swab result is available and the patient is transferred to an ordinary ward or to a COVID-19 ward if necessary.

The same applies for staff, who should be swabbed every 14 days in the ordinary area as long as the antibody test does not confirm very probable immunity [28]. Wearing a mask continues to be rational for all persons in the hospital until herd immunity is achieved. The same applies for reducing staff-patient contacts. It appears useful to test staff monthly for antibodies so that they can be deployed in the ordinary area without additional protective measures when there are sufficient immune staff members. Initially, operative management should concentrate especially on patients for whom postoperative ICU monitoring is very largely unlikely. The maximum number of admitted patients should initially be well below the hospital's maximum bed capacity, on the one hand to better ensure important hygiene conditions and also to allow rapid reaction at any time to a potential recurrence of a virus crisis. The same applies naturally for the maximum postoperative hospitalisation of patients, which should likewise be of manageable proportions.

\section{Summary/Conclusion}

In the acute pandemic, when the numbers of infection due to SARS-CoV-2 are increasing rapidly, it is necessary to adapt operating capacity to the current pandemic status and not postpone urgent operations. Freeing up and maximum sparing of relevant resources in the hospital are an important goal in an acute phase. Naturally, there are patients for whom acute or early surgery is indicated. When admitted to hospital, during inpatient care and in the operating theatre, strict hygiene regulations must be observed in order to protect the staff and other patients from infection and at the same time prevent uncontrolled spread in the hospital. These include taking swabs from patients to be admitted, mask wearing by patients and staff and the use of PPE with suspected and positive-tested cases. To ensure appropriate hygiene the hospital should be divided into areas for SARS-CoV-2-positive and negative patients and an area for investigation. Operations should, as far as possible, be performed only when the swab result is avail- 
able; otherwise every patient should initially be regarded as potentially SARS-CoV-2-positive. The operating theatre and team require special equipment if SARS-CoV-2 patients have to undergo surgery as there is a markedly increased infection risk due to intubation and extubation and also during the operation.

Conflict of Interest

The authors declare that they have no conflict of interest.

\section{References}

[1] Zou L, Ruan F, Huang M et al. SARS-CoV-2 viral load in upper respiratory specimens of infected patients. N Engl J Med 2020; 382: 1177-1179. doi:10.1056/NEJMc2001737

[2] Kampf G, Todt D, Pfaender S et al. Persistence of coronaviruses on inanimate surfaces and their inactivation with biocidal agents. J Hosp Infect 2020; 104: 246-251. doi:10.1016/j.jhin.2020.01.022

[3] Kramer A, Schwebke I, Kampf G. How long do nosocomial pathogens persist on inanimate surfaces? A systematic review. BMC Infect Dis 2006; 6: 130. doi:10.1186/1471-2334-6-130

[4] van Doremalen N, Bushmaker T, Morris DH et al. Aerosol and surface stability of SARS-CoV-2 as compared with SARS-CoV-1. N Engl J Med 2020; 382: 1564-1567. doi:10.1056/NEJMc2004973

[5] Bai Y, Yao L, Wei T et al. Presumed asymptomatic carrier transmission of COVID-19. JAMA 2020; 323: 1406-1407. doi:10.1001/jama.2020.2565

[6] Zhou M, Tang F, Wang $Y$ et al. Knowledge, attitude and practice regarding COVID-19 among health care workers in Henan, China. J Hosp Infect 2020; 105: 183-187. doi:10.1016/j.jhin.2020.04.012

[7] Li YK, Peng S, Li LQ et al. Clinical and transmission characteristics of Covid-19 - a retrospective study of 25 cases from a single thoracic surgery department. Curr Med Sci 2020; 40: 295-300. doi:10.1007/ s11596-020-2176-2

[8] Chu J, Yang N, Wei Y et al. Clinical characteristics of 54 medical staff with COVID-19: a retrospective study in a single center in Wuhan, China. J Med Virol 2020; 92: 807-813. doi:10.1002/jmv.25793

[9] Deutsche Gesellschaft für Orthopädie und Unfallchirurgie (DGOU). Dringliche Operationen: Empfehlungen für den Umgang mit Unfallverletzten und OP-Indikationen; 06.04.2020. Im Internet: https://dgou.de/ news/news/detailansicht/artikel/empfehlungen-fuer-den-umgang-mitunfallverletzten-und-op-indikationen-1/; Stand: 06.04.2020

[10] Offeddu V, Yung CF, Low MSF et al. Effectiveness of masks and respirators against respiratory infections in healthcare workers: a systematic review and meta-analysis. Clin Infect Dis 2017; 65: 1934-1942. doi:10.1093/cid/cix681

[11] Deutsche Gesellschaft für Allgemein- und Viszeralchirurgie e.V. COVID-19: Empfehlungen der DGAV e.V. Wiederaufnahme des Routinebetriebes; 24. April 2020. Im Internet: https://www.awmf.org/fileadmin/ user_upload/Stellungnahmen/Medizinische_Versorgung/DGAV_COVID_ Empfehlung2.pdf; Stand: 24.04.2020

[12] Kokkinakis I, Selby K, Favrat B et al. [Covid-19 diagnosis: clinical recommendations and performance of nasopharyngeal swab-PCR]. Rev Med Suisse 2020; 16: 699-701
[13] Corman VM, Landt O, Kaiser M et al. Detection of 2019 novel coronavirus (2019-nCoV) by real-time RT-PCR. Euro Surveill 2020; 25: 2000045. doi:10.2807/1560-7917.ES.2020.25.3.2000045

[14] Zhu J, Ji P, Pang J et al. Clinical characteristics of 3,062 COVID-19 patients: a meta-analysis. J Med Virol 2020. doi:10.1002/jmv.25884

[15] Li JY, You Z, Wang Q et al. The epidemic of 2019-novel-coronavirus (2019-nCoV) pneumonia and insights for emerging infectious diseases in the future. Microbes Infect 2020; 22: 80-85. doi:10.1016/j.micinf. 2020.02.002

[16] Wynants L, Van Calster B, Bonten MM] et al. Prediction models for diagnosis and prognosis of covid-19 infection: systematic review and critical appraisal. BMJ 2020; 369: m1328. doi:10.1136/bmj.m1328

[17] Cheng ZJ, Shan J. 2019 novel coronavirus: where we are and what we know. Infection 2020; 48: 155-163. doi:10.1007/s15010-020-01401-y

[18] World Health Organization (WHO). Clinical management of severe acute respiratory infection (SARI) when COVID-19 disease is suspected: interim guidance, 13 March 2020. Im Internet: https://apps.who.int/iris/ handle/10665/331446; Stand: 13.03.2020

[19] Ai T, Yang Z, Hou H et al. Correlation of chest CT and RT-PCR testing in coronavirus disease 2019 (COVID-19) in China: a report of 1014 cases. Radiology 2020. doi:10.1148/radiol.2020200642

[20] Casanova LM, Erukunuakpor K, Kraft CS et al. Assessing viral transfer during doffing of Ebola-level personal protective equipment in a biocontainment unit. Clin Infect Dis 2018; 66: 945-949. doi:10.1093/cid/cix956

[21] Robert Koch Institut (RKI). Rahmenkonzept Ebolafieber. Vorbereitungen auf Maßnahmen in Deutschland; Stand: 01.03.2019. Im Internet: https://www.rki.de/DE/Content/InfAZ/E/Ebola/Rahmenkonzept_Ebola. pdf? _blob=publicationFile; Stand: 01.03.2020

[22] Chang L, Yan Y, Wang L. Coronavirus Disease 2019: coronaviruses and blood safety. Transfus Med Rev 2020; 34: 75-80. doi:10.1016/j.tmrv. 2020.02.003

[23] Wang W, Xu Y, Gao R et al. Detection of SARS-CoV-2 in different types of clinical specimens. JAMA 2020; 323: 1843-1844. doi:10.1001/jama. 2020.3786

[24] Carli AV. CORR Insights ${ }^{\circledR}$ : surgeon personal protection: an underappreciated benefit of positive-pressure exhaust suits. Clin Orthop Relat Res 2018; 476: 1349-1351. doi:10.1097/01.blo.0000533609.68604.07

[25] Makovicka JL, Bingham JS, Patel KA et al. Surgeon personal protection: an underappreciated benefit of positive-pressure exhaust suits. Clin Orthop Relat Res 2018; 476: 1341-1348. doi:10.1007| s11999.0000000000000253

[26] Cook TM, El-Boghdadly K, McGuire B et al. Consensus guidelines for managing the airway in patients with COVID-19: Guidelines from the Difficult Airway Society, the Association of Anaesthetists the Intensive Care Society, the Faculty of Intensive Care Medicine and the Royal College of Anaesthetists. Anaesthesia 2020; 75: 785-799. doi:10.1111/ anae. 15054

[27] Wujtewicz M, Dylczyk-Sommer A, Aszkielowicz A et al. COVID-19 - what should anaethesiologists and intensivists know about it? Anaesthesiol Intensive Ther 2020; 52: 34-41. doi:10.5114/ait.2020.93756

[28] Barthold SW, Smith AL. Duration of challenge immunity to coronavirus JHM in mice. Arch Virol 1989; 107: 171-177. doi:10.1007/bf01317914 